\title{
A arteterapia em Jung e o seu potencial terapêutico como estratégia de intervenção humanizada no contexto escolar de jovens no ensino médio
}

\author{
Artetherapy in Jung and its therapeutic potential as a humanized intervention strategy in the \\ school context of young people in high school \\ El arte terapia en Jung y su potencial terapia como estrategia humanizada intervención en el \\ contexto escolar dos jóvenes no ensino médio
}

Recebido: 18/12/2021 | Revisado: 26/12/2021 | Aceito: 27/12/2021 | Publicado: 05/01/2022

\author{
Cristiano Matana \\ ORCID: https://orcid.org/0000-0002-6194-6209 \\ Universidade Franciscana, Brasil \\ E-mail: crismatana@terra.com.br \\ Janaína Pereira Pretto Carlesso \\ ORCID: https://orcid.org/0000-0001-8488-1906 \\ Universidade Franciscana, Brasil \\ E-mail: janaina.carlesso@ufn.edu.br \\ Juliane Marschall Morgenstern \\ ORCID: https://orcid.org/0000-0001-8478-3564 \\ Universidade Franciscana, Brasil \\ E-mail: julianemm@ufn.edu.br
}

\begin{abstract}
Resumo
O presente trabalho tem como objetivo buscar os fundamentos da arteterapia em Jung, afim de respaldar o seu potencial como estratégia de intervenção humanizada no contexto escolar de jovens do Ensino Médio. Este caracteriza-se como pesquisa bibliográfica e documental, de abordagem metodológica qualitativa. Jung foi um dos principais representantes da arteterapia no mundo e, por isso, coloca-se como base desse estudo. Foi o criador da psicologia analítica e desenvolveu o conceito de arteterapia e muitos dos princípios dessa técnica, em sua prática clínica a partir de 1920. Suas considerações influenciaram estudiosos no mundo inteiro, como por exemplo, Nise da Silveira (Brasil) e Margareth Naumburg (Norte Americana). Para Jung, os símbolos presentes no inconsciente individual e do coletivo se manifestavam na arte. E, por meio desta, o terapeuta pode percorrer um belo caminho de desvelamento junto do paciente, ajudando-o na tarefa difícil de interpretação na perspectiva de integração do seu Self e com seu ambiente. A arteterapia, e em nenhum momento foi proposto por Jung, deveria estar restringida à clínica. Nesse sentido, percebe-se um rico e amplo leque de conteúdos e técnicas que podem ser aplicadas com finalidades terapêuticas em muitos contextos. A educação, é um deles! A Base Nacional Comum Curricular (2018), percebe que a arte deve fazer parte da formação de crianças e jovens, desde a formação básica até o Ensino Médio. A escola, portanto, usando da arte na educação, pode torna-se uma ferramenta de apoio para a prevenção e promoção da saúde mental de jovens no Ensino Médio.
\end{abstract}

Palavras-chave: Arteterapia; Jung; Educação; BNCC; Saúde mental.

\begin{abstract}
This work aims to seek the foundations of art therapy in Jung, in order to support its potential as a humanized intervention strategy in the school context of high school youth. This is characterized as bibliographical and documentary research, with a qualitative methodological approach. Jung was one of the main representatives of art therapy in the world and, therefore, he is the basis for this study. He was the creator of analytical psychology and developed the concept of art therapy and many of the principles of this technique in his clinical practice from 1920 onwards. His considerations influenced scholars worldwide, such as Nise da Silveira (Brazil) and Margareth Naumburg (North-American). For Jung, the symbols present in the individual and collective unconscious were manifested in art. And, through this, the therapist can travel a beautiful path of unveiling with the patient, helping him in the difficult task of interpretation from the perspective of integrating his Self and his environment. Art therapy, and at no time was proposed by Jung, should be restricted to the clinic. In this sense, there is a rich and wide range of contents and techniques that can be applied for therapeutic purposes in many contexts. Education is one of them! The Common National Curriculum Base (2018) realizes that art should be part of the education of children and young people, from basic education to high school. The school, therefore, using art in education, can become a support tool for the prevention and promotion of the mental health of young people in high school.
\end{abstract}

Keywords: Art therapy; Jung; Education; BNCC; Mental health. 


\begin{abstract}
Resumen
Este trabajo tiene como objetivo buscar los fundamentos de la arteterapia en Jung, con el fin de apoyar su potencial como estrategia de intervención humanizada en el contexto escolar de los jóvenes de secundaria. Esta se caracteriza por ser una investigación bibliográfica y documental, con un enfoque metodológico cualitativo. Jung fue uno de los principales representantes de la arteterapia en el mundo y, por tanto, es la base de este estudio. Fue el creador de la psicología analítica y desarrolló el concepto de arteterapia y muchos de los principios de esta técnica en su práctica clínica a partir de 1920. Sus consideraciones influyeron en estudiosos de todo el mundo, como Nise da Silveira (Brasil) y Margareth Naumburg (Norteamérica). Americano). Para Jung, los símbolos presentes en el inconsciente individual y colectivo se manifestaron en el arte. Y, a través de esto, el terapeuta puede recorrer un hermoso camino de develamiento con el paciente, ayudándolo en la difícil tarea de interpretación desde la perspectiva de integrar su Yo y su entorno. La arteterapia, y en ningún momento fue propuesta por Jung, debería restringirse a la clínica. En este sentido, existe una rica y amplia gama de contenidos y técnicas que pueden aplicarse con fines terapéuticos en muchos contextos. ¡La educación es uno de ellos! La Common National Curriculum Base (2018) reconoce que el arte debe formar parte de la educación de niños y jóvenes, desde la educación básica hasta la secundaria. La escuela, por lo tanto, utilizando el arte en la educación, puede convertirse en una herramienta de apoyo para la prevención y promoción de la salud mental de los jóvenes en la escuela secundaria.
\end{abstract}

Palabras clave: Arteterapia; Jung; Educación; BNCC; Salud mental.

\title{
1. Introdução
}

A arteterapia como soma entre a arte e a função terapêutica que ela é capaz de produzir na pessoa, revolucionou muitos lugares de tratamento, especialmente a partir do início do século XX, com os trabalhos de Jung. Em sua obra "A Prática da Psicoterapia" (1985, p. 46) se vai perceber a utilização de técnicas expressivas no tratamento clínico de seus pacientes, na intenção de poder traduzir o "[...] indizível em formas visíveis". Dessa forma, ao tratar a arteterapia na psicologia analítica de Jung, primeiramente, quer-se resgatar os fundamentos desta, pois, ela viabiliza e respalda a aplicabilidade em outros contextos e públicos, que não necessariamente seja o ambiente clínico, como por exemplo, a escola.

Jung tornou-se referência mundial em arteterapia. Aqui no Brasil, por exemplo, pela década de 1940, sua ligação com a psiquiatra Nise da Silveira (1905-1999) contribuiu para um avanço exponencial na luta contra métodos de tratamentos utilizados os quais eram pouco ou nada eficazes tendo em vista uma progressão terapêutica que fosse benéfica para os pacientes psiquiátricos. A medicalização e eletrochoques, eram basicamente as formas avessas de "contenção" daqueles considerados como não sujeitos ou expurgos de uma sociedade. E o manicômio resumia-se mais como lugar de habitação desses rejeitados do que lugar humano de tratamento.

Nesse cenário pouco inspirador, havia uma necessidade de uma ação humanizada de tratamento, e a arteterapia vem na contracorrente para produzir sujeitos transformados pela arte e terapia associadas. Jung (na Suíça), Nise da Silveira (no Brasil), Margareth Naumburg (1890-1983 - nos Estados Unidos), entre outros, se ocuparam ao longo de suas vidas em melhor definir este conceito, também seu lugar de tratamento e a eficácia de sua prática. E o que se percebe, é que a arteterapia não se restringe exclusivamente ao ambiente clínico e ou hospitalar, muito pelo contrário. Os trabalhos nos Estados Unidos em arteterapia de Margareth Naumburg, educadora e psicóloga norte americana, foram levados e colocados à prova dentro da escola $^{1}$ no seu país de origem. O que facilitou a compreensão de que a arte, na sua expressão simbólica, atinge todos os indivíduos e lugares, e quando usada para fins terapêuticos, ajuda no desvelamento desses conteúdos (simbólicos). Ciornai (2004, p. 26), observa que Naumburg focalizava sua atenção no material inconsciente, "[...] expresso no trabalho de arte e no processo de compreensão do significado simbólico implícito nas imagens produzidas, solicitava e incentivava associações livres do paciente buscando promover a obtenção de insights sobre a imagética e o conteúdo simbólico dos conflitos inconscientes ali projetados".

\footnotetext{
${ }^{1}$ Ciornai (2004, p. 24) menciona que Naumburg ao voltar da Europa para os Estados Unidos, “[...] passou a dar aulas em escolas públicas utilizando o método Montessori... fundou em New York uma escola de vanguarda: a Escola Walden”.
} 
Observando o largo campo em que a arteterapia pode oferecer na área de prevenção e promoção da saúde mental, com distintos públicos e contextos, é que se faz alusão à temática da arte e educação. Como visto em Naumburgh, cujo trabalho foi embasado nos referenciais freudianos, mas sobretudo nos de Jung, a escola é um lugar possível de intervenção pela arteterapia. Ciornai $(2004,24)$ alude que a inovação do trabalho de Naumburg de arteterapia relacionada com a educação, sobremaneira se deu porque soube defender "[...] a importância da expressão dos conteúdos e motivações inconscientes para a educação e o desenvolvimento da personalidade".

Pensando na arteterapia como ferramenta possível de intervenção na escola, com aquele que a conduz (arteterapeuta), por meio de grupos de escolares de jovens do Ensino Médio, parece ser apropriada esta estratégia se considerar o gosto pela expressão, como sinônimo de individuação nessa faixa etária, pelo rico simbolismo que a arte é capaz de oferecer. Ademais, mesmo com todas as dificuldades de variados recursos humanos e materiais da escola pública, não seria difícil organizar oficinas de arteterapia. Em se tratando do arteterapeuta, como condutor do processo, fica a dica de Naumburgh (1971, p. xii, xiv apud Ciornai, 20004, p. 28-29) para se ter clareza naquilo que faz, pois, muitas vezes pode algum não diferenciar "arte como terapia" da "psicoterapia". E a ênfase deve estar na primeira, mais ainda em se tratando do ambiente escolar, mesmo que a segunda utilize aspectos da arte em suas intervenções.

[...] Arteterapia é concebida primariamente como um meio de fortalecer o ego, desenvolver o senso de identidade e o amadurecimento de forma geral. Sua função básica é vista no poder da arte de contribuir para o desenvolvimento de uma organização psíquica capaz de funcionar sob pressão sem fragmentar-se ou recorrer a medidas defensivas nefastas. Assim concebida, a arteterapia torna-se um componente essencial do contexto terapêutico e uma forma de terapia, que complementa ou apoia a psicoterapia mas não a substitui.

Retomando a relação arte e educação, no Brasil vislumbra-se esse binômio estampado na Base Nacional Comum Curricular - BNCC (BRASIL, 2018). Nela há um espaço bem delineado para que a arte encontre-se com a educação, favorecendo não só o ensino de suas linguagens - visual, dança, música e teatro, mas também sede lugar a um espaço de crescimento subjetivo, interpessoal e cultural. É nesse locus, em que a subjetivação vai se processando, que se vê o lugar favorável em que a arteterapia pode contribuir, em sua potência, como estratégia de intervenção para promoção da saúde mental desse público jovem de estudantes do Ensino Médio. Os números apontados por Estanislau e Bressan (2014, p. 13) se referindo aos problemas de saúde mental em crianças e jovens nas escolas brasileiras, impressionam, confirmando a necessidade de ações interventivas: “[...] contrariando a crença de que a infância é um período invariavelmente feliz, dados epidemiológicos brasileiros vêm alertando que 10 a $20 \%$ das crianças e adolescentes apresentam algum tipo de transtorno mental". Dessa forma, qualquer trabalho que possa contribuir para um justo equilíbrio e organização mental desses jovens, é sempre bem-vindo com satisfação pela escola, pelos pais destes e a própria sociedade.

Foi nesta intenção primeira, de unir arte e educação, e sua função terapêutica demonstrada pelos escritos de Jung sobre arteterapia, que este estudo tem sua intenção de responder o seguinte questionamento: a arteterapia projetada pelos estudos da psicologia analítica de Jung pode ser uma estratégia de intervenção humanizada para os jovens de escolas públicas do Ensino Médio?

Tal pergunta norteadora delineia o objetivo principal deste trabalho: buscar os fundamentos da arteterapia em Jung, afim de respaldar o seu potencial como estratégia de intervenção humanizada no contexto escolar de jovens do Ensino Médio, público. Três caminhos de investigação darão escopo para se chegar a tal fim: 1) Os fundamentos da arteterapia na psicologia analítica de Jung; 2) A arte na BNCC (Base Nacional Comum Curricular) e 3) Arteterapia como estratégia de intervenção terapêutica humanizada no contexto escolar dos jovens no ensino médio. 


\section{Metodologia}

O presente artigo caracteriza-se quanto à classificação de pesquisa da seguinte forma: a) quanto a sua natureza: básica; b) quanto a abordagem ao problema: qualitativa de base fenomenológica; c) quanto aos objetivos: exploratória, d) quanto aos procedimentos: bibliográfica e documental. Segundo Gil (2017) ao se referir a natureza básica da pesquisa menciona que esta compila estudos cujo propósito é de preencher lacunas do conhecimento. $\mathrm{O}$ autor descreve ainda que esta pode ser de dois tipos: básica pura e básica estratégica. A primeira tem a intenção de ampliar o conhecimento, sem preocupar-se com os possíveis benefícios. A segunda, direciona a obtenção de novos conhecimentos, em múltiplas áreas, levando em conta problemas práticos da realidade. Prodanov e Freitas (2013, p. 51) acrescentam dizendo que a pesquisa básica, além de gerar conhecimentos para o desenvolvimento das ciências, "Envolve verdades e interesses universais".

Minayo (2003) define a pesquisa qualitativa, do ponto de vista da forma de abordagem do problema, como sendo aquela que leva em consideração aspectos particulares da realidade estudada. A autora estabelece que nesse tipo de pesquisa trabalha-se com fatores não quantificáveis, assim, leva-se em consideração aspectos subjetivos do fenômeno pesquisado.

Prodanov e Freitas (2013, p. 54), descrevendo a pesquisa qualitativa na razão do ponto de vista dos procedimentos técnicos, afirmam que esta se desenvolve em base a materiais já publicados sobre tema: “[...] livros, revistas, publicações em periódicos e artigos científicos, jornais, boletins, monografias, dissertações, teses, material cartográfico, internet, com o objetivo de colocar o pesquisador em contato direto com todo material já escrito...”. Os mesmos autores ressalvam que os materiais que tem como fonte dados coletados da internet devem ser de procedência confiável, assim como a veracidade das citações e autorias. Sampieri et al. (2013, p. 33), afirmam que a coleta de dados neste tipo de pesquisa não utiliza medição numérica - tanto para descobrir ou aprimorar as perguntas da mesma em seu processo de interpretação. Além do que “[...] nos estudos qualitativos é possível desenvolver perguntas e hipóteses antes, durante e depois da coleta e da análise dos dados. Geralmente, essas atividades servem para primeiro descobrir quais são as perguntas de pesquisa mais importantes, e depois para aprimorá-las e responde-las".

A base fenomenológica neste tipo de pesquisa qualitativa quer expressar uma preocupação social relacionada com parte do cotidiano, do modo de viver das pessoas e seus problemas. Por um outro lado, não se fixa em definições de conceitos, como ocorre com pesquisas que seguem uma abordagem positivista. Suas técnicas são de natureza qualitativa e não estruturada (GIL, 2008). Em relação aos objetivos, a pesquisa qualifica-se como exploratória. Para Gil (2008, p. 27),

As pesquisas exploratórias têm como principal finalidade desenvolver, esclarecer e modificar conceitos e ideias, tendo em vista a formulação de problemas mais precisos ou hipóteses pesquisáveis para estudos posteriores. De todos os tipos de pesquisa, estas são as que apresentam menor rigidez no planejamento. Habitualmente envolvem levantamento bibliográfico e documental, entrevistas não padronizadas e estudos de caso... Pesquisas exploratórias são desenvolvidas com o objetivo de proporcionar vi- são geral, de tipo aproximativo, acerca de determinado fato. Este tipo de pesquisa é realizado especialmente quando o tema escolhido é pouco explorado e torna-se difícil sobre ele formular hipóteses precisas e operacionalizáveis.

No aspecto dos procedimentos, esta pesquisa define-se como bibliográfica e documental. Gil (2017) assevera a definição de revisão bibliográfica como uma forma de pesquisa que utiliza-se de materiais encontrados principalmente em livros, teses, jornais, revistas, dissertações e anais de eventos científicos. O mesmo autor acrescenta que, pela disseminação de novos aparatos de informação, passou-se a incluir fontes como, discos, Cds, fitas magnéticas e outros obtidos pela internet. Além disso, geralmente nesse tipo de pesquisa são usados materiais já publicados de diferentes autores e conteúdos, que irão ser selecionados dependendo do assunto a ser investigado pelo pesquisador. Nesta pesquisa, os materiais bibliográficos são todos nacionais, e a busca foi realizada nas bibliotecas físicas e virtuais. Estas últimas foram compostas a partir das seguintes 
bases de dados: Portal da CAPES, Scielo, Google Acadêmico e Pepsic, sendo usados os seguintes descritores: arteterapia; arteterapia e educação; arteterapia e Jung; arteterapia e saúde mental; Arte e BNCC (Base Nacional Comum Curricular).

Quanto aos critérios para seleção do material bibliográfico, primeiramente, em relação aos artigos, foi realizada a leitura de todos os resumos e os que tiverem relação com a temática estudada nessa pesquisa, será feita a leitura completa dos mesmos. Em relação aos livros, foram elencados e selecionados conforme a temática da pesquisa e dos capítulos; o método para análise e tratamento dos dados coletados seguirá as indicações de Lawrence Bardin (2002) na sua obra "Análise de Conteúdo", pelas três etapas básicas. A primeira delas é a pré-análise, ou seja, é a etapa da organização propriamente dita e seleção dos materiais disponíveis a respeito do assunto da pesquisa. Aqui alguns requisitos são citados por ela (BARDIN, 2002, p. 96-97): leitura flutuante: "[...] consiste em estabelecer contato com os documentos a analisar e em conhecer o texto deixando-se invadir pelas impressões"; escolha dos documentos: a priori ou selecionar os documentos coletados para análise - a posteriori; constituir o corpus: "[...] como conjunto dos documentos tidos em conta para serem submetidos aos procedimentos analíticos... implica, muitas vezes, escolhas, seleções e regras"; formular hipóteses e objetivos e, por último nesta etapa, preparar o material.

Referente a pesquisa documental, conforme Gil (2017), esta é muito utilizada, não exclusivamente, mas em praticamente todas as ciências sociais e, seus delineamentos maiores, do campo da História e da Economia. Há muitos pontos de semelhança com a pesquisa bibliográfica, na medida em que utilizam dados existentes. No entanto, a diferença fundamental reside na natureza das fontes, ou seja, enquanto a bibliográfica há um direcionamento dos autores em relação ao público e seus propósitos, a documental incorpora todo tipo de documentos, com múltiplas finalidades. Em síntese, pelo mesmo autor, diz-se que para ser documental os materiais (fonte documental) consultados são internos à organização, enquanto que os de cunho bibliográficos, quando as fontes extrapolam esses muros, como exemplo, as bibliotecas ou base de dados.

\section{Resultados e Discussão}

\subsection{Os fundamentos da arteterapia na psicologia analítica de Jung}

Carl Gustav Jung (1875-1961), fundador da psicologia analítica, respaldou uma leitura e intervenção com fins terapêuticos aos seus pacientes, pelo aspecto da arte. Pela psicologia analítica, o ser humano é visto por um prisma de integralidade, ou seja, não por um único aspecto da libido ${ }^{2}$ destinada a um objeto, como propunha Freud. Jung, por um outro lado, ampliou a noção desse conceito, a ponto de designá-la como energia psíquica, em geral, “[...] presente em tudo o que é tendência para..." (Laplanche \& Pontalis, 2016, p. 266). Uma destas tendências da libido, era a arte. A arte, portanto, em Jung, além do seu potencial criativo presente na pessoa, torna-se uma ferramenta com finalidades terapêuticas.

Em 1920, Jung “[...] foi o primeiro a fazer uso da expressão artística em consultório. Para ele, a simbolização do inconsciente individual e do coletivo se manifestava na arte. Nesse sentido, ele recorreu a linguagem expressiva como forma de tratamento, pedindo aos clientes que desenhassem livremente seus sonhos, sentimentos, conflitos, etc." (Cunha et al., 2017, p. 447). Mas foi somente a partir de 1969, com a fundação da AATA - Associação de Arteterapia Americana, que ARTE e TERAPIA se fundem numa única palavra, trazendo no seu escopo o conceito de tratamento psicológico pela arte (Souza, 2017).

No aspecto da arteterapia em Jung, olhando para o início de sua técnica, a intervenção do analista pela arte ultrapassa os limites de uma comunicação verbal, propiciando um alcance maior de tratamento não só para os neurotípicos, mas para os psicóticos e grupos diversos da sociedade. Esse dado na Psicologia analítica é muito importante de ser considerado, já que a psicanálise freudiana não avançou no tratamento dos psicóticos, apenas definiu um qualificativo "negativo" para se referir a

${ }^{2}$ Conforme Laplanche e Pontalis (2016, p. 265-266), a libido é “[...] energia postulada por Freud como substrato das transformações da pulsão sexual quanto ao objeto (deslocamento dos investimentos), quanto à meta (sublimação, por exemplo) e quanto à fonte da excitação sexual (diversidade das zonas erógenas)". 
impossibilidade de tratamento (Tenembaum, 2010), tampouco tratamentos para diferentes grupos sociais. Ao romper com Freud em 1914, pelo monismo na teoria da libido (Pinto, 2007), Jung "redesenha" muito de suas teorias e multidimensiona o tratamento. Assim, a partir da perspectiva de Jung, a arte passa a ser incluída como uma das formas de acesso ao inconsciente do indivíduo, com função terapêutica. As pinturas, modelagens, colagens, tecelagens, e muitas outras formas de expressão, ajudarão a pessoa no amadurecimento de sua personalidade, pela busca como processo contínuo de individuação, ou seja, tornar-se quem realmente é (Souza, 2017).

É interessante aqui falar desse conceito de "individuação" na teoria de Jung, porque aquilo que o indivíduo é capaz de expressar ou comunicar, é manifestação de seu inconsciente/consciente, e é o que o individualiza. O inconsciente tem uma amplitude muito maior que o consciente. É aquela parte que é constituída das muitas formações - pessoais, impessoais, familiares, sociais, culturais, étnicas - esses elementos constituem o inconsciente pessoal. Mas existe nessa mesma e grande parte, o inconsciente coletivo, formado por aquelas experiências que são comuns e compartilhadas a todos os indivíduos da espécie humana (Serbena, 2010).

Serbena (2010, p. 77) muito bem conceitualiza essas duas partes da psique em Jung, ressaltando-as para se poder alcançar a leitura, o modo de interpretação e a expressão do sentido e função da arteterapia no desenvolvimento de sua psicologia analítica. E as expressões por meio da arte, como se vai perceber, é o campo fluído que o inconsciente pode usar como potência de comunicação.

Devido a essa concepção ampliada de psique em Jung, pois inclui uma esfera coletiva e transcendente, ocorrem mudanças na concepção de consciência. Postula-se a existência da consciência do ego ou egóica que equivale à consciência no sentido do senso comum e da terminologia tradicional; e uma consciência ampliada, relativa à totalidade dos processos inconscientes e arquetípicos. Isso ocorre porque o inconsciente possui uma autonomia em relação ao ego, opera com muitas percepções que nem alcançam a consciência egóica e possui certas estruturas de imagens e comportamentos, os arquétipos, relativos a determinadas situações típicas e que funcionam como uma espécie de sabedoria instintiva e automática (Jung, 1924/1986; Whitmont, 1991). Isto é importante porque a consciência egóica opera principalmente pelo raciocínio causal e lógico, mas a consciência ampliada do inconsciente funciona por meio de analogias, associações e semelhança, sendo essencialmente imagética. Assim, o relacionamento entre o consciente e o inconsciente opera principalmente por meio da imagem e da imaginação.

Esses pontos de referência estabelecem um norte bem preciso a indicar a forma como essas duas realidades psíquicas inconsciente/consciente se relacionam, seja com o indivíduo ou deste com o meio e a cultura. Jung, pelo que foi destacado, indica que o inconsciente, essa parte ampla e analógica composta pelos sonhos, imagens, fantasias, mitos, não se comunica da mesma forma como o consciente - sendo este último a parte lógica e linear. Essa ressalva é bastante pertinente, pois ao querer tratar ambos com a mesma definição, se vai perder o que é elementar na psicologia analítica: o conceito de símbolo e arquétipo. O símbolo é um elemento constitutivo do psiquismo humano e é o que estabelece a conexão entre a consciência e o inconsciente (Serbena, 2010). Num fragmento da obra de Jung intitulada de "Tipos Psicológicos" (1991, p. 110-111), o autor caracteriza o símbolo sob dois aspectos na sua função: a dimensão criadora e outra que compreende o símbolo.

[...] o símbolo também pressupõe uma função que cria símbolos e uma outra função que entende o símbolo. Esta última não está compreendida na criação do símbolo; ela é, ao contrário, uma função em si que poderíamos chamar de pensar simbólico ou de compreensão do símbolo. A essência do símbolo consiste em apresentar uma situação que não é totalmente compreensível em si e só aponta intuitivamente para seu possível significado. A criação de um símbolo não é um processo racional, pois este não poderia gerar uma imagem que apresentasse um conteúdo, no fundo, incompreensível. A compreensão do símbolo exige uma certa intuição que capta, aproximadamente, o sentido desse símbolo criado e o incorpora na consciência. Esta função SCHILLER a denomina de um terceiro instinto, o instinto lúdico... 
Ao aprofundar o conceito de símbolo em Jung e ligando-o a arteterapia, percebe-se a nítida relação entre as produções e funções de ambos. Ou seja, entendendo que o símbolo na sua criação não é um processo racional, mas intuitivo e, portanto, não estabelecido pelo consciente, sua expressão pela arte se aproxima porque não pode ser traduzido simplesmente pelo lógico e pelo aspecto linear. É bastante complexo, mas parece que Jung conseguiu dar ao símbolo (no seu estado inconsciente) um sentido e um caminho de vinculação com a realidade por meio da arte, objetivando também sua função terapêutica a qual não mais estaria simplesmente atrelada a relação analista/paciente nas suas construções.

No criar de uma arte tem-se o "real" de um símbolo presente no inconsciente, mas também tem-se o indivíduo, o que compõe sua individuação. E na medida que o símbolo de alguma forma se materializa pela arte, o caminho de retorno ao inconsciente é também feito na medida em que se criam outros símbolos. Então, pode-se dizer que o símbolo, pela arte, tem esse caráter dual: do irreal ao real e vice versa. Como diz Jung (1941/1991, p. 115): "Se fosse apenas real, não seria símbolo; seria então um fenômeno real e, portanto, já não poderia ser símbolo. Simbólico só pode ser aquilo que encerra no um também o outro. Se fosse irreal, nada mais seria do que uma imaginação vazia que não se referiria a nada real e, dessa forma, também não seria símbolo".

Avançando na compreensão junguiana observa-se a convergência entre o símbolo e os arquétipos. O primeiro decorre de estruturas arquetípicas e "[...] representam situações e temas típicos e recorrentes da existência humana, tal como o nascimento, a morte, o casamento e a luta pela sobrevivência entre tantos outros e, deste modo, possuem uma constância de temas e significados, pois o arquétipo é uma estrutura do inconsciente, uma constante antropológica..." (Serbena, 2010, p.78). Dessa forma, vê-se que no inconsciente estão presentes as experiências pessoais e outra parte que é impessoal. É essa parte impessoal que Jung vai se referir como arquétipo ou como inconsciente coletivo.

Tomando a obra "Tipos Psicológicos" (Jung, 1991, p. 377) como referência, pode-se perceber que o autor traz uma definição sobre arquétipo, citando Kant, que expressa de forma simples e objetiva seu significado:

Esses arquétipos, cuja natureza íntima é inacessível à experiência, representam o sedimento do funcionamento psíquico da linha ancestral, isto é, das experiências do existir orgânico em geral, acumuladas em milhões de repetições e condensadas em tipos. Nesses arquétipos, portanto, estão representadas todas as experiências que tiveram lugar neste planeta, desde as mais remotas eras. São tanto mais nítidas no arquétipo quanto mais numerosas e intensas tiverem sido. Para usar a linguagem de KANT, o arquétipo seria uma espécie de noumenon da imagem que a intuição percebe e gera no perceber.

Ao caracterizar estas definições conceituais em Jung fica mais fácil de entender o porquê da "arte" entrar e ocupar um espaço privilegiado em seus estudos, tendo também uma função terapêutica (+ terapia). A arte não tem a obrigação de dizer ao intérprete seu significado, encerrando este na medida em que o artista a interpreta. Ao contrário, sua expressão está em fazer apelos à intuição e às experiências do outro, sempre num constante devir entre o artista (autor da obra) e o intérprete. Assim como o símbolo, a arte se fosse totalmente explicada, passaria para uma categoria de signo e se encerraria nela mesma. Fala-se isto para se entender que existe uma aproximação entre inconsciente/consciente e a arte por características semelhantes que os fazem manter uma síncrona comunicação entre o mundo interno e externo dos indivíduos. Em todos eles, os elementos contidos querem comunicar algo que lhes é próprio a partir da realidade do sujeito que mostra-se no seu processo de individuação - a arte também comunica a subjetividade. A arteterapia, nesse sentido, traz em si a dimensão da arte, e suas expressões, a qual (a arte) vai ser um, mas não o único, objeto de estudo da psicologia, porque o outro é o indivíduo autor da própria arte. Associado a este, a arteterapia vai cumprir uma de suas funções: terapêutica.

Adentrando na obra de Jung "O Espírito na arte e na ciência" (2013, p. 72) fica mais clara essa relação entre a arte, psicologia e o sujeito. 
Apesar de sua incomensurabilidade existe uma estreita conexão entre esses dois campos que pede uma análise direta. Essa relação baseia-se no fato de a arte, em sua manifestação, ser uma atividade psicológica e, como tal, pode e deve ser submetida a considerações de cunho psicológico; pois, sob este aspecto, ela, como toda atividade humana oriunda de causas psicológicas, é objeto da psicologia. Com esta afirmativa, também ocorre uma limitação definida quanto à aplicação do ponto de vista psicológico: Apenas aquele aspecto da arte que existe no processo de criação artística pode ser objeto da psicologia, não aquele que constitui o próprio ser da arte. Nesta segunda parte, ou seja, a pergunta sobre o que é a arte em si, não pode ser objeto de considerações psicológicas, mas apenas estético-artísticas.

Essa pontualização de Jung, no seu final, remete ao conceito de arteterapia na sua função terapêutica, cujo objeto não é a "arte em si", na busca pelo "belo", mas do sujeito que produz a arte e que traz por meio dela sua realidade interna para ser contemplada, organizada e, quando necessário, curada. Paín (2009) vai dizer que na arteterapia a arte é uma metáfora, em sua dupla condição: da pessoa que frequenta o ateliê e da arteterapia que demanda da arte um serviço útil. Na primeira, o indivíduo não se estabelece ali para cumprir regras de estética ou quaisquer outras que lhe exijam enquadramentos, como se estivesse ele numa universidade aprendendo técnicas de arte, cuja coerência estética deve estar mais próxima do "belo" - segundo o que é socialmente reconhecido. Na segunda - quando a arteterapia demanda da arte um serviço útil - "Este serviço terapêutico constitui a própria definição de arte, projetando simultaneamente sobre o paciente a tensão contraditória inerente à possibilidade de cura" (Paín, 2009, p. 12).

Jung (1991. p. 141) atribuiu tanto à arte um papel reconstrutor e integrador na sua psicologia analítica, que se for observada somente na obra "Tipos Psicológicos", ver-se-á inúmeras passagens que a definem, como também expressa seu sentido "[...] inter-mediador e reconciliador". Nesta passagem Jung já descrevia sobre um problema, que na atual modernidade líquida, segundo Bauman (2001), se expressa pela fragmentação do ser e das instituições. Esse fenômeno é o oposto do que propõe Jung, onde a psicologia prima pelo eixo integrador Self/Ego, cuja libido desempenha uma excelente função em dois aspectos que serão logo vistos. Mas antes, define-se libido como energia psíquica por detrás das imagens e símbolos, a possibilitar, como metáfora ou construto operacional, um entendimento dos inúmeros processos psíquicos (Serbena, 2010). O mesmo autor afirma que essa força ou energia psíquica enlaça o sujeito entre seu mundo interno com os objetos que estão externos a ele.

Em relação aos "aspectos" da libido, Jung aborda dois: o regressivo e o progressivo. O regressivo é denotado ou orientado para o que está dentro do sujeito, por exemplo: suas memórias, história pregressa e fantasias; já o progressivo, é orientado de forma oposta, ou seja, para o que está fora do sujeito - o externo, por exemplo: para os projetos e tempo futuro (Jung, 1985). Mas o que tem a ver a libido com a arteterapia em Jung? Se considerar a libido como essa força psíquica agente nesses dois polos de realidades, que não estão em oposição, percebe-se um movimento do ser na intenção de integrar, modificar-se a si mesmo e a "[...] realidade externa, cultural ou material" (Serbena, 2010, p. 78). A arteterapia percebe e tem essas mesmas intenções em relação ao sujeito e a realidade por meio da arte. Esta tem esse poder de transformar, unir, na tentativa de produzir vida em oposição ao fragmentado, ao caótico, ao desorganizado e o líquido.

Retomando a menção de Jung (1991, p. 141), ao se referir a arte como “[...] inter-mediador e reconciliador", há dois "estados", de natureza ímpar, que são de extrema relevância de serem considerados, pois situam o sujeito na relação com os dois polos acima mencionados: "estado dionisíaco", onde o grego fora arrebatado por sua própria natureza bárbara, inclusive de sua individualidade e de todos os seus componentes coletivos. Neste caso, a pior de todas as perdas está na sua individualidade; o "estado apolíneo", o homem esquece de si mesmo porque é tragado por seus instintos. Estes dois estados convergem para o que se pode definir como condição do "homem civilizado", segundo Jung. Mas "homem civilizado" para entrar na cultura tem que se submeter à ordem e suas regras sociais, causando um aprisionamento dos instintos, que não podem ser totalmente libertos, em razão da própria destruição do homem. 
Ao observar este arrazoado de Jung (1991, p. 141), vê-se que é necessário para o homem conter de alguma forma o estado apolíneo para estar na cultura - achando, equivocadamente, que isto é a "[...] autêntica beleza", no entanto, vai existir um represamento dos instintos, cuja forças são "[...] altamente destrutiva e, de longe, bem mais perigosas do que os instintos do primitivo que vive sempre modestamente seus instintos negativos". Este erro, segundo o mesmo autor, está "[...] numa falta profunda de conhecimento psicológico". Mas aqui Jung, citando Nietzsche e Schiller, aponta um liame "metafísico" "nessa problemática toda que, como foi dito, exerce o papel “[...] inter-mediador e reconciliador” (Jung, 1991, p. 141): a arte.

Mesmo que a discussão nessa obra de Jung vá muito além dos interesses desse estudo, o que convém colocar em relevo são estes papéis da arte na sua função simbólica. O símbolo guardado no inconsciente humano, produzido por ele nas suas ligações com o mundo externo, está fortemente conectado com suas imagens e produções no campo da arte. Então a arte associada a psicologia pode produzir um bem estar integrador e terapêutico, na medida que consegue ligar estes "universos" que fazem parte do indivíduo: inconsciente, consciente, cultura, ambiente e os próprios fenômenos que transcendem a ele mesmo. O terapeuta ou arteterapeuta, ou o próprio sujeito que busca integração, todos na tentativa de decifrar os inúmeros códigos expressos por meio da arte, devem buscar, como diz Jung (1991, p. 181), “[...] intuitivamente o grande valor da obra, sua relação com o mundo...". Isto é bem pontual porque, de fato, não existe artista e nem obra deste, sem que os universos internos e externos a ele (do artista) não estejam, de alguma forma, em comunicação - inclui-se aqui a expressão por meio da arte.

Em específico, do que esteja sob o olhar atento do terapeuta ou do arteterapeuta naquilo que o "artista" produz, em razão de um tratamento terapêutico, convém sempre a leitura apropriada dos símbolos expressos por meio da arte. Isto porque a própria arte pode estar tão subordinada "[...] à tirania da tradição que a obra é considerada apenas obra de arte e não o que realmente é, ou seja, um símbolo que significa uma renovação da vida. Para que saia da mera importância estética e chegue à realidade, deveria entrar na vida e aí ser assumida e vivida" (Jung, 1991, p. 181). A arte (com os seus símbolos e imagens), pelo que se observa na psicologia analítica de Jung, tem essa função de trazer à luz o material escondido do inconsciente, mas, isto é também função do terapeuta ou do arteterapeuta na medida em que consegue conectar e dar sentido a própria existência do indivíduo ou ao "todo" que é também seu. Dessa forma, se consegue entender, aprimorar e tornar eficaz esse outro aspecto da arte - tão belamente levada em conta nos escritos de Jung: sua função terapêutica.

Esse grafo sobre o que representam as imagens ligadas a arte, sintetizam um pouco do que foi dito nas próprias palavras de Jung (1991, p. 250): "Não se encontram ao sol e não são iluminadas por sol algum. Mas querem e devem sair de vez da noite. Isto seria arte: trazê-las para o sol e, assim, viveriam".

\subsection{A arte na BNCC (Base Nacional Comum Curricular)}

A arte, segundo a BNCC (Brasil, 2018), é composta pelas linguagens das Artes Visuais, Dança, Música e Teatro. É entendido, conforme o mesmo documento, que todas elas articulam saberes, mas também o campo da subjetividade, como por exemplo, a sensibilidade, intuição, pensamento, emoções, etc. É interessante que este conceito é ampliado e, com sentido, entra no campo dos diferentes saberes necessários para o bom desenvolvimento biopsíquico, até porque se compreende que o humano não é só intelecto, mas uma unidade composta por fenômenos múltiplos, inclusive sua cultura e habitat.

Nesse sentido que a BNCC (Brasil, 2018, p. 193) compreende que o indivíduo em formação, apropriando de uma ou mais linguagens que a arte produz no terreno de uma prática artística no ambiente escolar, está compartilhando e multidimensionando seus saberes, ensinando e aprendendo ao mesmo tempo, dialogando com os outros e com sua cultura. As manifestações artísticas, como por exemplo, “[...] exposições, saraus, espetáculos, performances, concertos, recitais, intervenções e outras apresentações e eventos artísticos e culturais, na escola ou em outros locais...”, como os processos de

${ }^{3}$ Segundo Jung (1949/1991, p. 143) "Metafísica tem para nós aqui a conotação psicológica de inconsciente". 
criação que estes envolvem, tem que serem compreendidos como relevantes no seu todo - para o próprio sujeito, sua família, para a escola e para a sociedade.

No tangente as linguagens da arte, a BNCC (Brasil, 2018) propõe que esta articule seis (6) dimensões do conhecimento, pois, isto é também o que singulariza a experiência artística e do próprio sujeito que a produz. São eles: criação, crítica, estesia, expressão, fruição e reflexão. Algumas características destas dimensões cabem ser ressaltadas aqui pelo propósito do trabalho.

Conforme a BNCC (Brasil, 2018, p. 194-195) a "criação", além do nome já sugerir sua intenção lógica, está ligada a “[...] uma atitude intencional e investigativa que confere materialidade estética a sentimentos, ideias, desejos e representações em processos, acontecimentos e produções artísticas individuais ou coletivas"; "crítica": aqui vê-se o sujeito, que é capaz de expressar-se pela arte, trazer os elementos de seu tempo e sua história. Portanto, esta dimensão "[...] articula ação e pensamento propositivos, envolvendo aspectos estéticos, políticos, históricos, filosóficos, sociais, econômicos e culturais"; estesia: aqui o corpo é a principal linguagem da arte. "Essa dimensão articula a sensibilidade e a percepção, tomadas como forma de conhecer a si mesmo, o outro e o mundo"; expressão: é o sujeito, que pela arte, sente necessidade de exteriorizar-se (manifestar-se) por suas produções artísticas, seja por aquilo que é seu ou pelo aspecto coletivo. "Essa dimensão emerge da experiência artística com os elementos constitutivos de cada linguagem, dos seus vocabulários específicos e das suas

Materialidades"; fruição: ligada ao prazer que a arte produz no sujeito; reflexão: é o sujeito que reflete sobre seu próprio agir artístico, "[...] seja como criador, seja como leitor".

Todo esse conjunto de conhecimentos quer possibilitar a comunicação e articulação entre a subjetividade do indivíduo (sua realidade interna), o mundo e sua cultura (realidades externas a ele). Tudo num agir, literalmente, comunicativo proporcionado pela arte. E a arte, contemplada na BNCC (2018, p. 196), pode se interligar aos muitos outros componentes curriculares, na intenção de construir uma rede de interlocução capaz, inclusive, de construir projetos em parceria observando os tempos etários e vivenciais da pessoa.

Por esse ponto último, a BNCC (Brasil, 2018) divide o ensino da linguagem da arte em dois tempos escolares: do $1^{\circ}$ ao $5^{\circ}$ anos (etapa da educação infantil) e do $6^{\circ}$ ao $9^{\circ}$ anos (etapa do ensino fundamental). Em cada um desses, além de serem respeitadas as condições etárias e de desenvolvimento, as unidades temáticas, objetos de conhecimentos e habilidades, variam. Por exemplo, para o ensino básico, as unidades temáticas são a música, teatro e artes integradas, enquanto que no ensino fundamental, são as artes visuais e a dança. No Ensino Médio a arte está presente no item "A área de Linguagens e suas Tecnologias", visando oportunizar uma "[...] consolidação e a ampliação das habilidades de uso e de reflexão sobre as linguagens - artísticas, corporais e verbais (oral ou visual-motora, como Libras, e escrita) -, que são objeto de seus diferentes componentes (Arte, Educação Física, Língua Inglesa e Língua Portuguesa” (p. 482).

Pela mesma base documental, vê-se o tema da arte no Ensino Médio como caminho que propulsiona a intuição e o lúdico, além disso, contribui com o conhecimento do próprio sujeito, do outro e de suas relações com o mundo que compartilha. Salienta-se que há um reconhecimento da fase de transição, complexa, em que vivem esses jovens, sendo necessário para eles compreenderem seus “[...] sentimentos, interesses, capacidades intelectuais...” (Brasil, 2018, p. 481), bem como suas expressões que devem ter lugar de expressão. Nesse momento de vida, há também a necessidade dos vínculos sociais e grupais, que favorecem o processo de individuação. Os afetos se abrem em novas perspectivas. "Encontram-se diante de questionamentos sobre si próprios e seus projetos de vida, vivendo juventudes marcadas por contextos socioculturais diversos" (Brasil, 2018, p. 481).

Esses dados apresentados pela BNCC (Brasil, 2018, p. 482) enfatizam que há "Um ambiente propício para o engajamento dos estudantes em processos criativos...”, e a arte e suas linguagens favorecem essa comunicação e interação do indivíduo com o outro, com o mundo, sua cultura e todas as situações (favoráveis ou não) que circundam estes. Num campo 
aberto de possibilidades que a arte pode se fazer nesse meio, como uma linguagem, é mister, como o documento assim expressa, que esteja voltada para a transformação, “[...] crescimento e reelaboração de poéticas individuais e coletivas".

As considerações que a BNCC (Brasil, 2018, p. 483) faz, situando esse jovem a partir de sua subjetividade, de sua realidade histórica e social, são muito importantes, porque possibilita ver mais claramente onde o trabalho com arte pode, com seu instrumental de ferramentas e linguagens, colaborar para esse processo saudável de desenvolvimento. Não faltam indicações no documento, por exemplo:

O trabalho com a Arte no Ensino Médio deve promover o entrelaçamento de culturas e saberes, possibilitando aos estudantes o acesso e a interação com as distintas manifestações culturais populares presentes na sua comunidade. $\mathrm{O}$ mesmo deve ocorrer com outras manifestações presentes nos centros culturais, museus e outros espaços, de modo a propiciar o exercício da crítica, da apreciação e da fruição de exposições, concertos, apresentações musicais e de dança, filmes, peças de teatro, poemas e obras literárias, entre outros, garantindo o respeito e a valorização das diversas culturas presentes na formação da sociedade brasileira, especialmente as de matrizes indígena e africana. Nesse sentido, é fundamental que os estudantes possam assumir o papel de protagonistas como apreciadores e como artistas, criadores e curadores, de modo consciente, ético, crítico e autônomo, em saraus, performances, intervenções, happenings, produções em videoarte, animações, web arte e outras manifestações e/ou eventos artísticos e culturais, a ser realizados na escola e em outros locais. Assim, devem poder fazer uso de materiais, instrumentos e recursos convencionais, alternativos e digitais, em diferentes meios e tecnologias.

Percebe-se que a BNCC (Brasil, 2018) deixa em aberto o uso dos instrumentais e recursos para a produção de arte. É compreensível se a arte for considerada o "infinito" da razão infinita do próprio sujeito que se expressa por ela, ou seja, não há limites para sua expressão. Mesmo os "limitados" pela razão, sempre encontram nela um espaço em que a arte torna-se vida.

A arte ligada a vida e a vida ligada a arte, sempre estiveram entrelaçadas, produzindo conhecimentos e linguagens que possibilitam comunicações. É tamanha essa relação que a história da humanidade guarda esses esboços, não só como um sinal do que faziam os homens primitivos ou pela história contada por meio da arte, mas porque nela (a arte) é revelado, de uma certa forma, o íntimo e características daquele (a) que a produz. A arte seria, nesse sentido, uma "assinatura" muito pessoal do indivíduo. A BNCC, ao considerar a arte enquanto área do conhecimento, reconhece, também por meio dela e de seu potencial inventivo e criativo, que os sujeitos encontram meios para se subjetivarem - o que não deixa de ser uma assinatura.

\subsection{Arteterapia como estratégia de intervenção terapêutica humanizada no contexto escolar dos jovens no ensino médio}

No Brasil a arteterapia teve sua grande alavancada e visibilidade pelo trabalho da psiquiatra Nise da Silveira (19051999) no hospital D. Pedro II, em Engenho de Dentro, no Rio de Janeiro. Foi no ano de 1946 que ela assume a Sessão de terapêutica Ocupacional, conduzindo seus pacientes a variadas atividades expressivas (sobretudo pintura e modelagem). Nise entendia que a arte, ao menos aplicada no tratamento dos pacientes, não tinha a intenção de ser "medida" ou quantificada na expressão do belo, nem de distraí-lo, mas sobretudo de “[...] contribuir efetivamente para a cura dos pacientes” (Reis, 2014, p. 146). Não foi de sua intenção nomear seu trabalho como "arteterapia", mas "terapêutica ocupacional". Sua ligação com Jung e com vários outros estudiosos aqui no Brasil, os quais foram se ligando ao seu projeto, tornou este uma referência de tratamentos "alternativos" frente aos horrores cometidos nos manicômios da época - relatados por ela na obra "O mundo das Imagens" (Silveira, 2001, p. 17).

A Seção de Terapêutica Ocupacional desenvolveu-se progressivamente até instalar dezessete núcleos de atividade. Todas as atividades proporcionavam condições para a expressão das vivências de seus frequentadores. Paralelamente, estimulava-se neles o fortalecimento do ego e um avanço no relacionamento com o meio social, levando-se sempre em consideração suas possibilidades adaptativas atuais.

Dentre as várias atividades ocupacionais, verificamos que a pintura e a modelagem permitiam mais fácil acesso ao mundo interno do esquizofrênico. E esse é o nosso principal objetivo, não só como uma questão teórica, mas também como necessidade para o tratamento, uma vez que teríamos de encontrar a atividade adequada à 
condição psíquica em que se encontra o indivíduo. Além disso, já havíamos verificado, desde 1948, que a pintura e a modelagem tinham em si mesmas qualidades terapêuticas, pois davam forma as forças emocionais tumultuosas, despotencializando-as, e objetivavam autocurativas que se moviam em direção à consciência, isto é, à realidade. Foi por esses dois motivos - compreensão do processo psicótico e valor terapêutico - que da Seção de Terapêutica Ocupacional nasceu o Museu de Imagens do Inconsciente, inaugurado em 20 de maio de 1952, numa pequena sala.

$\mathrm{O}$ trabalho de Nise ofereceu ancoragem para todos os trabalhos posteriores que surgiram de arteterapia - ao menos por aqui no Brasil. E apesar da arteterapia por aqui ter sido muito mais voltada para o âmbito da psiquiatria, sua relevância de tratamento se estende a múltiplas áreas, como a do ensino. Ocupando-se do trabalho de uma das arteterapeutas de renome americano, Margareth Naumburg (1890-1983), percebe-se que seu método de ensino, que incluía a arte, foi de importância proeminente.

Naumburg, muito tempo antes de se tornar arteterapeuta, foi uma educadora ousada para seu tempo. Sua formação incluiu áreas como a da psicologia (experimental, psicanálise) e parapsicologia. Na cidade de Roma participou de cursos de formação do método Montessori, o qual deu muita base para seu trabalho posterior. Sua formação artística, associada a toda essa bagagem, a fez fundar, em Nova York, a Escola Walden. Com muita destreza e aptidão, um dos seus legados em matéria de ensino foi defender e colocar em relevo "[...] a importância da expressão dos conteúdos e motivações inconscientes para a educação e o desenvolvimento da personalidade" (Ciornai, 2004, p. 24).

Quando se olha para trabalhos como este de Naumburg, associando a arteterapia e a educação, se percebe o quanto de potencial tem essa dupla associação se aplicada às crianças e jovens em uma escola. As palavras dessa autora muito bem expressam o que ela mesma conseguiu consolidar por meio de suas experiências com arteterapia e educação: "A convicção de que a expressão livre na arte é uma forma simbólica de linguagem nas crianças, básica a toda a educação, cresceu através dos anos. Concluí que esta expressão espontânea na arte poderia ser básica também para o tratamento psicoterápico" (Naumburg, 1966, p. 30 apud Ciornai, 2004, p. 25).

Muito embora Naumburg tenha posteriormente se dedicado mais a dar palestras e a escrever livros, deixando sua irmã (Florence) no cuidado da Walden, a obra publicada em 1947, com o título "Estudos sobre a expressão livre na 'arte' de crianças e adolescentes com problemas de comportamento como meio de diagnóstico e terapia”, foi um "[...] marco importante na história da arteterapia por ter sido o primeiro na área" (Ciornai, 2004, p. 25). Jungue e Asawa (1994, p. 22 apud Ciornai, 2004, p. 25) vão dizer que “[...] Naumburg não foi a primeira a utilizar o termo 'arteterapia', mas ficou conhecida como a 'mãe' da arteterapia por ter sido a primeira a claramente diferenciá-la como um campo específico, estabelecendo os fundamentos teóricos sólidos para seu desenvolvimento".

Em se tratando do que a arteterapia pode oferecer a alunos, por exemplo, de ensino médio de escolas públicas, o campo se abriria largamente pelas muitas necessidades destes. Mas como este aluno se situa num ambiente escolar, convém, antes, atentar para as muitas problemáticas que tanto ele como a escola enfrentam. A escola, primeiramente, sofre com a falta de incentivos econômicos e de recursos humanos e físicos, além de políticas públicas incipientes para enfrentar estas e outras dificuldades. Na atual conjuntura social, a fragmentação e as desestruturas familiares também incidem diretamente na vida e nos processos de ensino e aprendizagem desses jovens. A transferência de responsabilidades nesses casos é muito frequente, e a escola torna-se a "escolhida" para cumprir um papel que não é de sua função. Vasconcelos (1995, p. 22) ao observar estas questões, afirma: "Percebemos muitas famílias desestruturadas, desorientadas, com hierarquia de valores invertida em relação à escola, transferindo responsabilidades suas para a escola..., [...] a família não está cumprindo sua tarefa de fazer a iniciação civilizatória: estabelecer limites, desenvolver hábitos básicos”.

Em relação aos jovens escolares no Ensino Médio, de um modo geral, não são desconhecidas algumas das problemáticas que estes enfrentam nessa fase: os conflitos de vida que ganham um peso maior nesta transição entre a 
adolescência e a vida adulta, onde estão tentando um lugar onde possam melhor se situar; os emocionais/comportamentais; baixo rendimento escolar, quando não devidamente auxiliados e estimulados por pais e educadores; evasão escolar; drogas; sexualidade; relações familiares conturbadas; falta de apoio social; falta de condições econômicas e de emprego; falta de um espaço na escola onde se possa promover a saúde mental e a prevenção dos transtornos mentais, assim como o incentivo da aprendizagem socioemocional deste jovem, etc.

Ao perceber os dados epidemiológicos aqui no Brasil apontadas por Estanislau e Bressan (2014, p. 13) dos problemas de transtornos mentais, relacionados às crianças e jovens, espanta-se:

Contrariando a crença de que a infância é um período invariavelmente feliz, dados epidemiológicos brasileiros vêm alertando que 10 a $20 \%$ das crianças e adolescentes apresentam algum tipo de transtorno mental... Além da alta prevalência, o impacto dos transtornos psiquiátricos na vida do indivíduo - aferido pelo Índice de Incapacidade por Doença (Global Burden of Disease) - é considerado o mais prejudicial entre todos os problemas médicos na população dos 10 aos 24 anos. A situação no Brasil é particularmente alarmante se considerarmos a proporção continental do País e as enormes diferenças culturais e sociais entre as regiões.

O que justifica ainda mais a necessidade de apoio, atenção psicossocial e formas de intervenção humanizadas, e a escola é um espaço privilegiado. E se for levado em conta esse tempo de pandemia, onde crianças e jovens perderam muito do contato relacional com professores e colegas presencialmente, por ficarem mais reclusos em seus lares num período de quase dois anos, muitos problemas de ordem psicossociais se agravaram. Comenta-se isto porque no retorno à escola dessas crianças e jovens, nesse período de quase pós-pandemia, a mesma enfrentará maiores dificuldades do que aquelas citadas anteriormente, pela demanda maior relacionados a estes (problemas). Quando se fala em escola, entende-se que seja uma preocupação dos pais, professores e da própria sociedade. Entretanto, nesse momento, frisa-se a importância dos professores pela melhor condução de todo esse processo.

Não é desculpa que escolas públicas, mesmo com todas as dificuldades e falta de recursos que enfrentam, possam se omitir do cuidado psicossocial de qualquer aluno. Mesmo com a falta de um serviço especializado que atenda essa área na escola, as parcerias e encaminhamentos adequados são muito importantes, ainda mais em épocas difíceis que em que se vive. Por exemplo: as universidades tem cada vez mais se disponibilizado a prestar um serviço de atendimento psicossocial à escola - seja local, remoto ou em ambiente supervisionado de clínica-escola, com seus professores e estagiários - propiciando acolhimento, formação de educadores escolares e atendimentos aos alunos. Alternativas como esta, ou, como dito, por meio da arteterapia, trazem um fôlego à escola na medida que esta se sente apoiada e atendida em necessidades bem específicas, as quais somente um tratamento mais especializado pode contribuir para uma melhor qualidade de vida e de saúde psíquica de todo o quadro.

As muitas formas de "promover" a saúde, inclui-se a saúde mental na escola, bem como as parcerias para que se possa alcançar melhores resultados nesse sentido, está amparada pelas Leis de Diretrizes e Bases da educação Nacional (9.394), e da construção dos Parâmetros Curriculares Nacionais. Estanislau e Bressan (2014, p. 17) afirmam:

Os parâmetros Curriculares Nacionais estão em congruência com os princípios de promoção de saúde em escolas indicados pela OMS, ou seja, buscam a sustentação da saúde e do aprendizado, além de integrar profissionais de saúde, educação, pais, alunos e membros da comunidade, ajudando a transformar a escola em um lugar saudável e propício ao bem-estar, ao crescimento e ao desenvolvimento. Além dessas iniciativas, outras propostas tem reforçado a importância da escola na busca pelo desenvolvimento saudável de crianças e adolescentes no Brasil e no mundo.

As indicações desses autores corroboram para reforçar o desenvolvimento e aplicação de projetos. Ainda que se saiba das dificuldades, a gestão escolar, como dito anteriormente, pode buscar meios possíveis para implementação. E ao sugerir nessa pesquisa a arteterapia como instrumento terapêutico para o trabalho com os jovens do Ensino Médio, foi pensando 
exatamente em respaldar a necessidade de atenção psicossocial, seja voltada aos professores, mas sobretudo, pelas porcentagens assustadoras, como mostradas acima, que estão a indicar números cada vez mais crescentes de jovens com transtornos mentais. A arteterapia, falando de prevenção e promoção da saúde mental na escola, torna-se uma excelente ferramenta terapêutica de apoio, inclusive não dispendiosa, e pode ser um caminho de comunicação ativa deste jovem na busca de autoconhecimento, de auto estima, de relações mais saudáveis (entre pais, professores, colegas, etc.), de descobertas de seu próprio potencial criativo, etc. Mas o que se salienta aqui é o potencial que a arte tem para comunicar, de forma terapêutica, aquilo que nem sempre aparece: o mundo interno da pessoa - como foi dito por Jung no capítulo anterior, com seus conflitos, desejos, tendo em vista a integração e organização do ser.

$\mathrm{O}$ trabalho do arteterapeuta torna-se singular no ambiente da escola, podendo fazer oficinas em grupos com jovens, sempre intentando provocar o ato criativo pelo estímulo que os materiais propiciam. É a imaginação, o inconsciente, o consciente, as narrativas de suas histórias de vida que extravasam num agir comunicativo por meio da arte. Urrutigaray (2011, p. 21) menciona que "A percepção das imagens e das formas pelo autor da obra pode, pela condução do arteterapeuta como mediador do processo, trazer clarificação ou conscientização de acontecimentos psíquicos não identificados ou não percebidos". Esta menção do autor demonstra algumas finalidades principais que a arteterapia vai procurar desempenhar junto do adolescente, ou seja, com a arte expressa por ele, de forma livre, é função do arteterapeuta ajudá-lo na clarificação ou conscientização do que pode estar ainda insignificado para esta pessoa, tangente, produzindo angústias, agressividades e outros transtornos.

Sobre a expressão do aluno, que mostra seu "insignificado" numa obra de sua produção, talvez muitos artistas de renome, formados em belas-artes, seguindo o rigor de uma formação e dos padrões de arte, olhem e não considerem seu valor como tal, ou nem sejam capazes de compreender sua significância psicológica e terapêutica. Mas não se está falando aqui desse tipo de "arte", cujo rigor e padrões associados definem o artista sendo bom ou mal na sua produção do belo. A arteterapia nunca quis, desde seu início, ser levada em conta por isso. Jung (1985, p. 45-46) vai precisar o conceito o qual querse aplicar com este jovem em necessidade, deixando claro que o aspecto da arte, ligado à sua forma terapêutica de intervenção, transcende esses padrões. E isto é um outro ponto que o arteterapeuta deve estar muito atento para que as sessões possam progredir e atingir a eficácia de produção e tratamento.

Ainda que ocasionalmente os meus pacientes produzam obras de grande beleza, boas para serem expostas em mostras de "arte" moderna, eu as considero totalmente desprovidas de valor artístico, quando medidas pelos padrões da arte verdadeira. É essencial até que não tenham valor, pois, do contrário, meus pacientes poderiam considerar-se artistas, e isso seria fugir totalmente à finalidade do exercício. Não é arte, e aliás, nem deve sê-lo. É bem mais que isso; é algo bem diverso do que simplesmente arte; trata-se da eficácia da vida sobre o próprio paciente. Aquilo que do ponto de vista social não é valorizado passa a ocupar aqui o primeiro plano, isto é, o sentido da vida individual, que faz com que o paciente se esforce por traduzir o indizível em formas visíveis. Desajeitadamente. Como uma criança. Mas, afinal, por que razão levo os pacientes a se exprimirem por meio de um pincel, de um lápis, de uma pena, quando atingem um certo estágio em sua evolução?

Antes de mais nada, o que interessa é que se produza um efeito.

Jung (1985, p. 46-47) nesse postulado, termina afirmando a necessidade do "efeito" que a arte produz na pessoa. Mas em se tratando de jovens de ensino médio, em grupo de afins, se for pensar nos efeitos que a arteterapia pode produzir, quais se pensaria? Seu valor e finalidade seriam os mesmos se aplicado a outros públicos etários e em diferentes contextos que não o da clínica? Pela leitura dos parágrafos seguintes desta célebre obra de Jung, pensa-se que sim! Por exemplo: quando este fala da pintura, que é uma das formas em que a arte pode se expressar, tendo outras que poderão ser consideradas, esta produz efeitos incontestáveis, porém, bastante difíceis de descrever, segundo ele. 
Basta, por exemplo, que um paciente perceba que, por diversas vezes, o fato de pintar um quadro o liberta de um estado psíquico deplorável, para que ele lance mão desse recurso cada vez que seu estado piora. $\mathrm{O}$ valor dessa descoberta é inestimável, pois é o primeiro passo para a independência, a passagem para o estado psicológico adulto. Usando esse método - se me for permitido usar este termo - o paciente pode tomar-se independente em sua criatividade. Já não depende dos sonhos, nem dos conhecimentos do médico, pois, ao pintar-se a si mesmo digamos assim - ele está se plasmando. O que pinta são fantasias ativas - aquilo que está mobilizado dentro de si. E o que está mobilizado é ele mesmo, mas já não mais no sentido equivocado anterior, quando considerava que o seu "eu" pessoal e o seu "self" eram uma e a mesma coisa. Agora há um sentido novo, que antes the era desconhecido: seu eu aparece como objeto, como objeto daquilo que está atuando dentro dele. Numa série interminável de quadros, o paciente esforça-se por representar, exaustivamente, o que sente mobilizado dentro de si, para descobrir, finalmente, que é o eterno desconhecido, o eternamente outro, o fundo mais fundo da nossa alma.

Interessante que Jung (1985, p. 47), imediatamente, nesta mesma obra, fale do jovem e das mudanças que estão sendo processadas, interna e externamente a ele - muito provavelmente por demonstrar uma certa preocupação na formação e ajustamento do eu nesse novo momento em que se situa. Nessa fase, apesar das inúmeras situações de caos na vida do jovem, há uma necessidade imperiosa de ajustamento, bem como [...] formar o seu eu consciente da maneira mais eficaz possível, isto é, educar a sua vontade". No acompanhamento das sessões de arteterapia com estes na escola, o arteterapeuta também se torna um guia, que ao interpretar com o autor da "arte" (conjuntamente), vai traçando caminhos novos que possam colaborar para esse ajustamento, equilibrando a vontade e os desejos do jovem (moderados ou não), os quais incidem diretamente na sua vida e em seus projetos presentes e futuros. Com isto, não se está preconizando uma série de normativas de condução de seus trabalhos que envolvem a arte, pois se isto acontecesse, muito provavelmente o aspecto da arte teria uma outra conotação, como já mencionado, como nas universidades pelos padrões rígidos de métrica por vezes estabelecidos; já pelo aspecto da terapia, seria sugestão. E tanto uma quanto a outra fracassariam em suas intenções, pois o aspecto da fluidez e liberdade do inconsciente e da pessoa são essenciais para um desenvolvimento sério de um trabalho em arteterapia - em qualquer ambiente em que se esteja sendo aplicado.

A aproximação da arte + terapia do jovem no ensino médio escolar, como se percebe, tem o grande potencial de ajudá-lo em seus maiores desafios nessa fase de vida, especialmente seus ajustamentos internos (eu) e externos (a realidade). E quando outros "facilitadores" (desde os pais, professores, amigos, colegas, educadores psicossociais etc.) se colocam disponíveis, compreensíveis e empáticos em querer colaborar com todo esse processo de desenvolvimento (bio-psico-social) em que o jovem se situa, muito mais o fim terapêutico é alcançado. Ao considerar as palavras de Jung (1985, p. 37) quando afirma que a vida do jovem, normalmente, [...] está sob o signo de uma expansão geral, em vista de uma meta precisa a ser atingida. Parece que a sua neurose provém sobretudo da hesitação ou do recuo diante do rumo a seguir”, tem-se uma ideia precisa do quanto é significativo para ele essa rede de apoio formada em seu entorno. E se nesse momento da idade o jovem procura "expandir", os processos de ensino-aprendizagem, a família, novas formas de intervenção na escola e a sociedade, etc., precisam estar imbuídos daquilo que é essencial na arte: a criatividade. Para esta, nas palavras de Urrutigaray (2011, p. 32), "[...] o processo de criação sempre nos confere novas significações" ao infinito do ser e de sua construção permanente.

\section{Considerações Finais}

$\mathrm{O}$ tema deste trabalho sobre arteterapia aliou três eixos de investigação: a arteterapia na psicologia analítica de Jung, a arte na BNCC e a arteterapia como estratégia de intervenção terapêutica humanizada no contexto escolar dos jovens no ensino médio. Ao ser construído tal referencial, percebeu-se que há poucas bibliografias e estudos nessa área da arteterapia associada ao contexto da educação, muito embora, haja um grande leque de possibilidades em que a arteterapia pode colaborar. Um desses nichos, como estudado, foi a área do Ensino, especificamente, com jovens de Ensino Médio. 
No concernente ao primeiro eixo, a abordagem junguiana sobre arteterapia, apesar de que muitos arteterapeutas seguiram (em) referenciais, concomitantes, de psicanálise e da psicologia analítica de Jung, como Margareth Naumburg, há uma preponderância pelo segundo (Jung). Não por um acaso, se for considerado que Freud tratou o "artístico" no sujeito de forma muito insipiente nos seus estudos, sobretudo na leitura dos sonhos. Freud utilizou-se da arte, basicamente, pelo viés clínico, sobretudo insistindo que esta poderia servir como catarse, ou seja, um expurgo do material indesejado presente no inconsciente - em síntese, a arte foi concebida por ele (Freud) como um produto de uma neurose.

Diferentemente de Freud, Jung percebia que os símbolos, como representações no inconsciente, não existiam em razão simplesmente de uma catarse. Estes faziam parte de uma expressão do inconsciente individual e do coletivo, que se expressam pela arte no sujeito que a produz. E aqui está a grande relevância dos estudos de Jung sobre arteterapia, ou seja, a arte encontrada e produzida pelo sujeito, era uma das "chaves" para ajudar a desvendá-lo como também de produzir nele um efeito terapêutico, como ficou explícito em sua obra "A prática da Psicoterapia” (1985).

Levando isto em conta e os demais escritos, os quais muitos ficaram explicitados ao longo desse trabalho, considerase que Jung foi o "pai" da arteterapia. Seus seguidores pelo mundo inteiro conseguiram perceber que esta (a arteterapia) poderia ir muito além do ambiente da clínica e colocaram esta técnica em múltiplas áreas, como da psiquiatria, com Nise da Silveira, aqui no Brasil, e da Educação, com Margareth Naumburg, nos Estados Unidos.

A arteterapia, como ferramenta terapêutica, mostrou-se muito eficaz nesses espaços citados de tratamento e, sem dúvida alguma, humanizando especialmente a clínica psiquiátrica hospitalar. Já no ambiente do Ensino, mesmo que Jung não tenha trabalhado arteterapia nesse lugar, inspirou os trabalhos de Margareth Naumburg na Escola Walden, de New York. Sua dedicação em arteterapia, aplicada na escola, trouxe provas de que a arteterapia de Jung tinha alcance muito maior do que ele próprio imaginou, ao mesmo tempo, foi incentivo para outras (escolas) que poderiam se servir desses recursos e promover a saúde mental de crianças e jovens.

Como se percebe, foi a partir dos desdobramentos dos estudos da arteterapia de Jung, que chega-se ao espaço escolar. A finalidade desse processo inicial na clínica de Jung, com a arteterapia, também foi preservada e estendida a esses outros lugares, ou seja, fazendo uso da expressão artística, manifesta como linguagem do inconsciente/consciente, o sujeito se comunica terapeuticamente. É uma lástima que toda essa evolução alcançada por esses estudos, na relação arteterapia e educação, tenham incidido ainda pouco na realidade escolar de jovens e crianças, com esse intuito terapêutico. Talvez seja ainda necessário "desbravar" mais, de modo que fique claro, tanto para os acadêmicos, educadores, psicopedagogos, psicólogos que trabalham com educação, que a arteterapia pode oferecer muito de si para uma estratégia de promoção e prevenção de saúde mental na escola.

Vale ressaltar, que a BNCC, como ficou claro pelo estudo realizado neste trabalho, no segundo eixo, abriu portas para as inúmeras propostas que possam se desenvolver na escola que tenham como base a arte e suas linguagens. A arte, ali mencionada, inclui saberes, relações, expressão, cultura, mas, sobretudo, subjetividade. E é nesse sentido último, no campo da subjetividade, pois não se faz arte sem o sujeito e o que se inclui nele como experiência, que a arteterapia pode dispor à escola e aos alunos, seu aparato de ferramentas para trabalhar a saúde mental, seja pela linguagem da arte visual, pela Dança, pela Música e o Teatro. Em todas essas linguagens, é possível unir arte + terapia.

No terceiro eixo, o qual moveu essencialmente a pesquisa deste trabalho, tem-se a Escola como um propício ambiente de construção do saber, mas lugar, também, de promoção de saúde mental, como foi muito bem dito por Estanislau e Bressan (2014). Apesar dos números crescentes apontados por esses autores mostrarem a realidade brasileira como preocupante em relação as crianças e jovens com transtornos mentais, o foco não deve ser a absolutização do sintoma (transtorno) presente nestes, mas a prevenção e promoção da saúde. Numa cultura da medicalização, onde os sintomas são supostamente extirpados com estas, como único meio, infelizmente tratamentos menos ou nada agressivos são cada vez mais 
deixados de lado. É nesse sentido, que a escola deveria, levando em conta os dados da realidade, ver formas alternativas para viabilizar projetos que contemplem esta imperiosa necessidade. Isso, além de significar muito para ela mesma (a escola), mais ainda significaria para as crianças e jovens e suas respectivas famílias.

De toda forma, esta pesquisa quis mostrar que a arteterapia, iniciada pelos trabalhos de Jung, pode ser útil à Escola no aspecto da prevenção e promoção da saúde mental nessa faixa etária de jovens adolescentes do Ensino Médio, público. E se for considerado a tríade, apontada pelos autores Estanislau e Bressan (2014), nas abordagens da saúde mental em escolas (eficácia, segurança e custo benefício), crê-se que ela (arteterapia) está apta para ser desenvolvida como programa permanente em escolas. É claro que a capacitação de profissionais nessa área é elementar, o que não quer dizer que estes tenham que ser, necessariamente, da psicologia. Hoje no Brasil existem muitos cursos de capacitação, inclusive destinados a educadores e psicopedagogos, que colaboram para a viabilidade de projetos de arteterapia na escola por meio de múltiplas oficinas de arte.

Entender que a escola não quer unicamente uma criança ou jovem dotados de capacidades intelectuais pelo ensino, mas pessoas saudáveis (de corpo e mente) e realizadas, talvez seja um primeiro passo para que projetos assim sejam melhor valorizados. Portanto, o ensino e a expressão artística por meio da arte, associados a prevenção e promoção da saúde na escola, não são "matérias” acessórias como muitos pensam, é qualidade integral de e para a vida.

\section{Referências}

Bardin, L (2002). Análise de Conteúdo. Edições 70.

Bauman, Z. (2001). Modernidade líquida. Zahar.

Brasi (2018). Ministério da Educação. Base Nacional Comum Curricular.

Ciornai, S. (2004). Percursos em arteterapia: arteterapia gestáltica, arte em psicoterapia, supervisão em arteterapia. (2a. ed.). Summus. 62.

Cunha, E. F. B., Batalha, K. E. C., \& Madeira, T. S., Olimpio (2017), A arteterapia na perspectiva junguiana: expressão psíquica e transformação do ser. Univiçosa. 9 (1) 447-452.

Estanislau, G. M, Bressan. R. A. (2014). Saúde Mental na Escola: o que os educadores devem saber. Artmed.

Gil, A. C. (2006). Como elaborar projetos de pesquisa. (4a.ed.). Atlas.

GIL, A. C. (2008). Métodos e técnicas de pesquisa social. (6a. ed.) Atlas.

Jung, C. G. (1985). A prática da psicoterapia. Vozes. 6.

Jung, C. G. (1991). Tipos Psicológicos. (6a. ed.). Vozes.

Jung, C. G. (2013). O espírito na arte e na ciência. Vozes.

Laplanche, J, \& Pontalis, J.-B. (2016). Vocabulário da psicanálise. (4 ed.) Martins Fontes.

Minayo, M. C. S. (2003). Pesquisa social: teoria, método e criatividade. (22a. ed.). Vozes.

Paín, S. (2009). Os fundamentos da arteterapia. Vozes.

Pinto, K. M. (2007). Crônica de um fim anunciado: o debate entre Freud e Jung sobre a teoria da libido. Ágora, 10 (1), $75-88$.

Prodanov, C. C., Freitas, E. C. (2013). Metodologia do trabalho científico: métodos e técnicas da pesquisa e do trabalho acadêmico. (2a ed.), Feevale.

Reis, A. C. (2014) Arteterapia: a arte como instrumento no trabalho do Psicólogo. Psicologia: Ciência e Profissão. 34(1), 142-157.

Sampieri, R. H., Collado, C. F., \& Lucio, M. D. P. B. (2013). Metodologia de pesquisa. (5a. ed.). Penso - Artmed.

Serbena, C. A. (2010). Considerações sobre o inconsciente: mito, símbolo e arquétipo na psicologia analítica. Revista da Abordagem Gestáltica, 16 (1), 76-82.

Silveira, N. (2001). O mundo das imagens. Ática.

Souza, O. R. S (2017). O Encontro com o sagrado na arteterapia orientada pela teoria Junguiana. Dissertação (Mestrado Profissional) - Est. São Leopoldo-Rs, 91. 
Research, Society and Development, v. 11, n. 1, e24811124916, 2022

(CC BY 4.0) | ISSN 2525-3409 | DOI: http://dx.doi.org/10.33448/rsd-v11i1.24916

Tenembaum, D. (2010). Investigando psicanaliticamente as psicoses. (2a. ed.). Rubio.

Urrutigaray, M. C. (2011). Arteterapia: a transformação pessoal pelas imagens. (5a ed.). Walk.

Vasconcellos, C. S. (1995). Disciplina: construção da disciplina consciente e interativa em sala de aula e na escola. Libertad. 